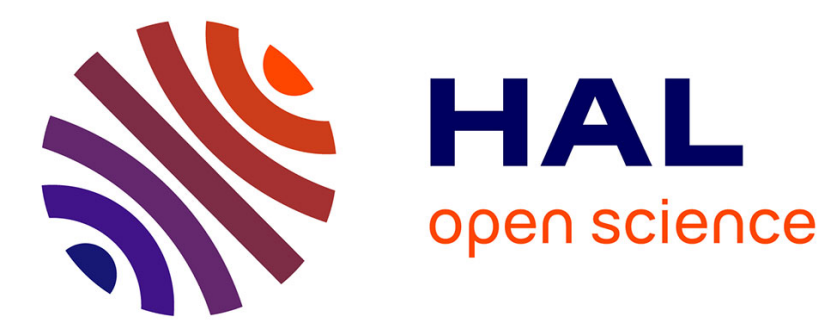

\title{
INTERNET ARTWORKS, ARTISTS AND COMPUTER PROGRAMMERS: SHARING THE CREATIVE PROCESS
}

\author{
Jean-Paul Fourmentraux
}

\section{- To cite this version:}

Jean-Paul Fourmentraux. INTERNET ARTWORKS, ARTISTS AND COMPUTER PROGRAMMERS: SHARING THE CREATIVE PROCESS. LEONARDO - MIT Press, 2006, Vol. 39 (No. 1). sic_00109117

\section{HAL Id: sic_00109117 \\ https://archivesic.ccsd.cnrs.fr/sic_00109117}

Submitted on 23 Oct 2006

HAL is a multi-disciplinary open access archive for the deposit and dissemination of scientific research documents, whether they are published or not. The documents may come from teaching and research institutions in France or abroad, or from public or private research centers.
L'archive ouverte pluridisciplinaire $\mathbf{H A L}$, est destinée au dépôt et à la diffusion de documents scientifiques de niveau recherche, publiés ou non, émanant des établissements d'enseignement et de recherche français ou étrangers, des laboratoires publics ou privés. 


\section{INTERNET ARTWORKS, ARTISTS AND COMPUTER PROGRAMMERS: SHARING THE CREATIVE PROCESS}

Jean-Paul FOURMENTRAUX

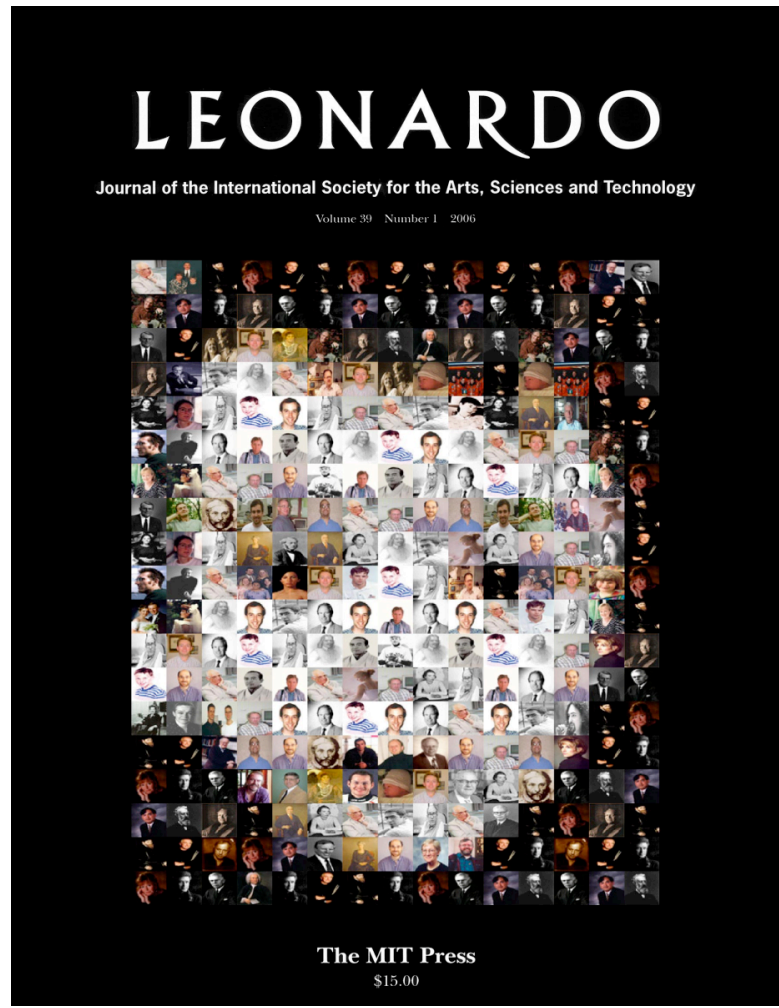

- Version "auteur" avant parution. Pour toute citation, toujours se référer à l'article publié : FOURMENTRAUX JP. 2006 « Internet artwork, artists and computer programmer : sharing the creative process », Leonardo MIT Press, Volume 39, Issue 1, pp. 44-50. 


\begin{abstract}
Internet artwork no longer refers to the concept of a finalized object, but rather to a dynamic process, a collective, open and interactive device. Due to the increasing sophistication of tools, the design of an Internet artwork now requires hybrid skills. The necessary cooperation with computer specialists in order to create suitable programs thus changes the status of the artwork and its author. This paper presents an ethnographic case study of cooperation between a computer programmer and an artist. It examines the processes of shared design, negotiated authorship and artwork appropriation. From an analysis of the means of communication, various technical media and "intermediary tools," the author focuses on role allocation, task sharing and artwork appropriation as the artwork is modified throughout the creative process.
\end{abstract}


Collaborative situations between artists and important "extra personnel," composed of all those who, in various ways, contribute to the realization of the work, are numerous in the history of artistic practice. Although these artworks are the results of collective activity, the different contributions to production are often hidden to benefit the mythical figure of the singular author, the final guarantor for "the cardinal activity of art" [1]. In the case of Net Art, the interactivity postulated as a technical imperative of the work requires computing skills that the artist does not always possess. Computer programmers are needed for the algorithmic programming of the artistic dispositiv[2]. Observation of the spaces of mediation, translation and negotiation enables a better understanding of the ways in which a plan begun through individual initiative can evolve into a shared work. From this point of view, the digital arts involve a simultaneous redefining of an artwork's localization (i.e. where or what exactly is the artwork?) and of the responsibilities of its authors. Certain questions arise:

-What is it that makes us consider a work of Net Art to be an artwork? How do the perspectives of the artist and the computer programmer differ in terms of what constitutes the artwork?

-How do these different partners proceed to share the activities of conception? What are the tasks attributed to each one at the beginning of the plan? What are the tasks that each one is in charge of in practice? Who is responsible for what? Who is the author?

The following analysis deals with the conception and realization of Des_Frags [3], a project by artist Reynald Drouhin [4] made in association with computer programmer Sebastien Courvoisier at the French International Center of Video Cre- ation (CICV) [5]. The ethnographic observations of the artwork's conception were conducted primarily through three periods of residential research at $\mathrm{CICV}$. The materials from which these observations are drawn include: an observation report; computer models, diagrams, 
interfaces and specification notebooks used by different actors; a series of interviews with the artist and the computer programmer; and all the email conversations that guided the activity of conception. This survey, an unpublished research report, is part of a research contract financed by the Plastics Arts Delegation of the French Ministry of Culture and Communication, from the Contemporary Art and Scientific Culture program.

Des_Frags is an on-line software program that allows users to link a keyword with an image from their hard drive or the Internet. After a period of time, they receive an e-mail containing a mosaic image that is a recomposition of the original image but composed of images found on-line that are related to the user's chosen word. A study of Des_Frags offers a better understanding of the specificities of flow: The artist returns to the collaborative conditions of the work's conception and installs, rather than actualizes, a software system. This study focuses on the conception and design of this artwork and on the distribution of roles, allocation of tasks and different perspectives [6] of the work held by the various participants. I take a close look at the role of communication tools in this process, the various technical mediations [7] and intermediary objects [8] mobilized by the different partners to translate their individual interests to their common purpose. These media aids for communication and action can become negotiation partners. They influence the conception process through their anticipation and description values, and also affect the control and authentication of the plan. In order to get closer to these "translation" and "negotiation" processes [9], I have chosen, in this text, to restrict my study to observation of the shared conception of the user interface. Computer programming, ergonomic development, aesthetic coherence and design are concurrently called for in this work of technical and aesthetic production. The sociological aim here is to consider the technical problems and the social contexts together, and to produce both an analysis of aesthetic and/or technical debates and a sociological analysis of the implied actors [10]. 


\section{BETWEEN PROSCENIUM AND BACKSTAGE: THE DISPOSITIV OF NET ART}

Des_Frags proposes a dispositiv for, by and with the Internet, one that can only exist and unfurl on-line. This dispositiv is unique to Net Art and requires the use of preexisting elements on the Web (in this case, still images) to compose a mosaic-image.

Des_Frags functions by asking an Internet user to select an initial static image, either from the Internet or from his/her own archives. This original image provides the pattern upon which other images scavenged from the Web are displayed. With the help of a search engine designed for this purpose, the user, or "internaut," is then asked to collect a large number of other images by using no more than three keywords. These thumbnail images are then incorporated into the final mosaic. The pragmatic conditions under which this process of artistic creation occurs (as well as the strategies and conventions of its design, application and circulation) work to renew the systems, existence and expression of the work of art. What is the artwork in this context? What are its characteristics? Between proscenium and backstage, how is the artwork simultaneously recognized, perceived and activated? The role of the CICV in this collaboration focused on the development of a computer program to gather different, preexisting fragments of Internet applications, and on the conception of the user interface. The interface needed to enable both the search for mosaic images and the submission of the image matrix. This process entails three main stages: (1) The expert evaluation of the artistic plan (its conceptualization); (2) The technical development of the work, encompassing both technical and aesthetic solutions to programming requirements; (3) The valuation/exhibition of the work (its final aim). Each of these stages went through numerous mediations - technical, human, institutional - and indicated a progression in the collaborative process. 


\section{Institutional Enrollment in the Project}

Drouhin met with the CICV staff before beginning work with Courvoisier alone. This first encounter between the artist and the CICV staff was particularly rich because its main purpose was to make the artist specify the characteristics of a plan that was still being formulated. Little by little, a situation of give-and-take took place between the different partners. On several occasions during the course of the evaluation, the artist was asked to reframe his plan and to make choices that would aid its technical development, just as the artist waited for the computer programmers to tell him the possible options. The artist was compelled, even as he was asking for more information, to come to a decision on various options, to the point that the interactions between artist and programmers became so en tangled as to raise questions about who exactly formulated, refined, transformed and/or abandoned the options.

The CICV roots collaborations in an institutional context that contributes to the structuring of activities and thus, by putting the different actors in clearly distinct roles, tends to limit the possible ambiguity of positions. This system defines the identities and roles of each person, makes expectations and purposes clear and highlights potential difficulties. When an entangled web of problems and options (aesthetic, institutional, ethical, technical, etc.) is encountered, resolution in the name of a common purpose is undertaken by some of the actors according to their assigned roles. Not just anybody can ask any question, just as not just anybody can answer any question. The technical partners are "in the service" of the artist's plan; the artist is the sole designer and legitimate initiator. The different knowledge sets and practices of the various actors are thus inscribed in a history of specialties: art history, and more precisely aesthetic sense, on the one hand and the history of discoveries and technical innovation on the other hand. However, the boundaries between these knowledge sets and practices that appear to be stable and clearly defined are susceptible to contagions in the apparent "immediacy" of concrete collaborations. 


\section{The Intermediary Space of the Collaboration}

All of these transactions fall within the scope of a shared work space that revolves around an art/technical axis. The transfer of competencies and the translations of knowledge sets and practices occur at the junction of these two domains. Therefore, it was often difficult to separate what were strictly the computer programmer's concerns from those of the artist. The two partners tried to create an intermediary space of exchange, a territory "in between" where the confrontation of interests and work methods could take place. Even though the institutional context of the exchange acted as a stabilizing influence by separating the expertise and tasks of the collaborators, these same collaborators had to battle with objects and technical devices that nevertheless affected the relationships between collaborators. The interface constituted the support and the medium from which the shared conception went forward. This technical object is here viewed as an "analyzer" - support and mediator — of the conceiving action. In this way the interface acted as a bridge to link the opposing actors and help them.

As design of the interface was the final stage of the project's conception, its necessary anticipation led the artist and the computer programmer to successively outline intermediary steps. Indeed, as the technical choices were collectively evaluated, kept or dismissed, anticipation of the interface's uses prompted a listing and definition of its formal parameters and technical options. There was an ongoing negotiation throughout the conception process with regard to the interface's appearance and the technical requirements of its functions. Two preliminary attempts at designing the interface preceded its final form. The first, initiated by the artist, was strictly functional and clearly imperfect as far as its formal appearance was concerned. This initial model turned out to be too technical and abstract for a novice user. The second attempt was the result of the computer programmer's work, which redesigned the interface with the double aim of technical experimentation and testing its functionality. This redesign 
attempted to give a visual illustration for each of the interactive parameters, so that the user could see an example of the possible results of each interface function.

Courvoisier: There was a moment when a lot of people at the heart of CICV did not really understand the use and meaning of the interface functions and options. It was at that time that I settled on small images, little icons that tried to show, in the easiest possible way, the results that this could give according to the different parameters. Reynald told me that it was something he hadn't thought about and he's going to integrate it in the final interface. So there maybe, there's an influence.

Courvoisier's initiative went far beyond the strictly technical responsibilities assumed to be those of the computer programmer. His contribution gave not only a technical meaning to the whole interactive process, but also a plastic and visual form that influenced, in an important way, the design of the final interface. However, though the artist seemed receptive to the readability offered by the addition of the illustrative vignettes, he was nevertheless hesitant to use the icons, which he judged too descriptive for each of the functions.

Drouhin: The way the options are set... I don't think that I'll present them this way when I redo the interface. He [Courvoisier] didn't have the vocation either to present things or to draw the interface.... What's funny is that he did not put it crudely... He put red characters on a black background...and even if it's sure that we won't keep any of these elements, it's interesting that he presented it this way.... It's ugly. It's not a value judgment but.... It's presented as a technician would do it, there's no vocation to be aesthetic here. 
Drouhin was naturally inclined to retain control of those elements that he perceived as belonging to the field of his own competences. The third and definitive version of the interface was undertaken solely by Drouhin. Its visual design is minimal and sober, consisting of black characters on a white background. The artist conceived each of the menus. The different options are referred to by simple terms, with no descriptive or explanatory overstatement. Nevertheless, the path from the first model to the final version of the interface was the result of a long process of borrowings and shared suggestions, readable through the final, hybrid and collective design (Fig. 1).

The collaborative realization of the artistic and technical interface, both as artwork and tool, led to multiple collective and individual appropriations of the different dimensions of the plan. The different negotiations focused alternately on the aesthetic and technical stakes of the artwork and of the software program; the realization of the interface in its plastic (formal) and technical (functional) dimension; its appearance, ergonomics, options; and finally on the appropriation and signature of the dispositiv. During this conception, in the "in-between" of the exchange, the artwork was truly an unlimited "everything," invested as much by the artist as by the computer programmer. At the boundaries of the cooperation, interests and motivations were intertwined. The artist became the initiator and discoverer of computer solutions. The computer programmer claimed his creative sense and intervened in aesthetic choices and in the artistic appraisal of the plan and its interface. The compromises negotiated between the artist and the computer programmer were governed by two opposite logics: one of coherence with the artistic plan, its aesthetic concept and visual form, and one of adaptation to technical constraints, feasibility and technical implications. 


\section{des frags}

defragmentation of the internet *

follow steps \# 1 to \# 9 to defragment the internet with images. or just $=9$

to generate an image which is randomly fragmented.

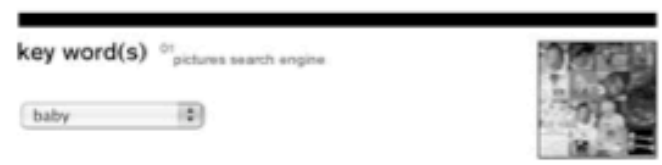

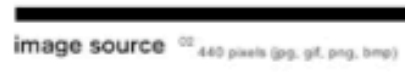

Choinir le fichier) sucun fichier selectionne
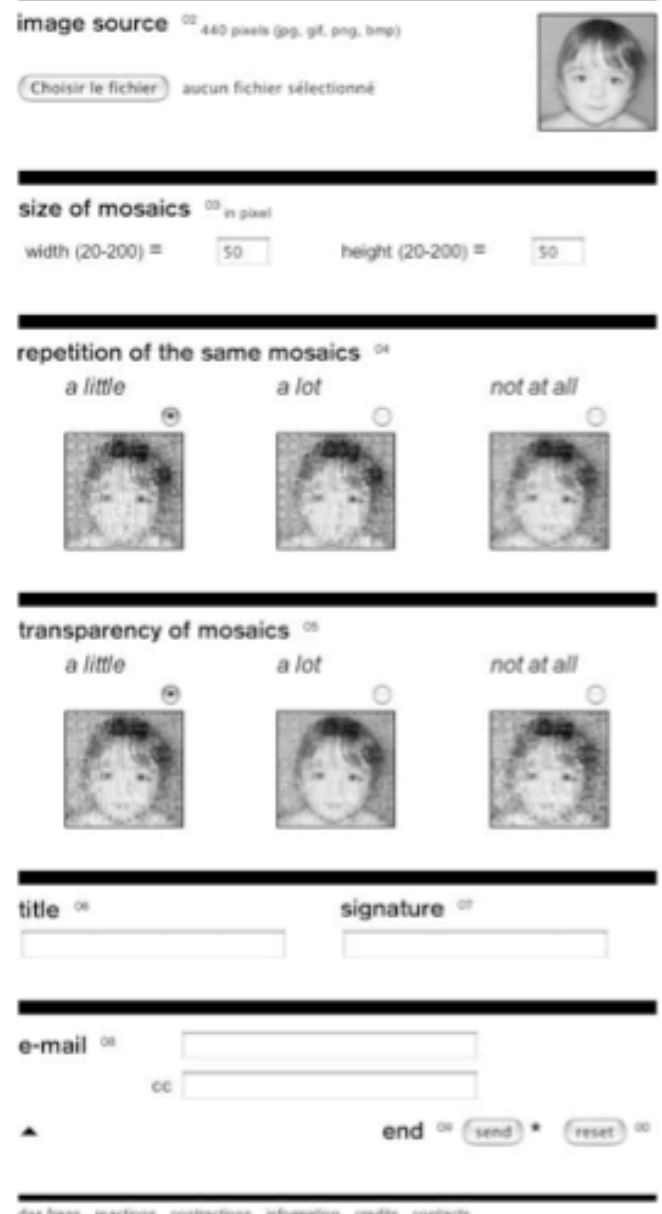

Fig. 1. Screenshot of the third and final interface of Des_Frags.

(৫ Reynald Drouhin)

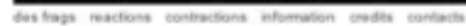




\section{RECONSTRUCTION OF STATUS AND ROLES}

If these boundaries of action were crossed during the shared activity of conception, they reappeared in an intensified form in interviews with the artist and the computer programmer post-conception. At the plan's close, desires and often frustrations reemerged, encouraged by the demand of reflexiveness inherent in an interview format. So, in the "information" column of the Des_Frags site, the status of the collaborators reemerged as delimited and reinforced by a separation and confrontation of points of view (Fig. 2).

Fig. 2. Screenshot of the Des_Frags artistic and technical information. (C) Reynald Drouhin) information

Defragmentation of the Internet by Images: With the aid of one or several "key words": to determine the images that will be researched (mosaic modules) to recompose the image that you have submitted (the matrix). "Des frags" is a project using the resources available on the Net and to put them to a different purpose than that for which they were originally designed. For this, the project is, in appearance, very simple: using existing tools available on the web to create the final work (from/by and with the Net). "Des frags" is the defragmentation of the Internet... A multitude of information is available on the web, and this project allows all this information to coexist together in the one final image: a matrix that will serve as a global reference point of the different elements of which it is composed.

"Des frags" is also a "blow" (a murder for players of video games).. meaning a "hold-up" of existing images on the Net: the appropriation of a raw material present on the web and reactivation of this "dead", archived memory into a live, ephemeral memory.

information

Defragmentation of the Internet: creating the positive association of autonomous, specific and dispersed resources: diverting contingent functions to channel them towards an open finality: going beyond the discordant multiplicity of languages and types of information to make a "melting pot" with a new coherence.

It all comes down to the creation of an ensemble of mutualist applications (in PHP and MySQL) allowing for the transparent circulation of the

information from one pre-existing tool to another: the web based text

translation engine of SystranSoft (for the automatic translation of key words from French to English), the "Yahoo" web-engine for the research of images (for the recuperation of mosaics), the "Metapixel" photomosaic composition programme (for the final rendition), a collection of image processing programmes from ImageMagick (for the degradation of the "contradictions") all this through a simple HTML interface.

"Des frags" also uses system processing (Linux) which is brutally dissociated from its parent, with the information extracted by breaking certain "web windows" - a continuous breakage whose splinters, far-away and indeterminate, are recomposed into a familiar image. 
The artistic information roots the work in art history and artistic practice. The technical information inscribes the dispositiv development in technical innovation and in the history of computer programming. As a result, the various contributions appear more from the angle of complementarity than from one of possible hybridization. This discrepancy of points of view finds its equivalent in differentiated modes of designation of the dispositiv. Des_Frags, following the example of digital creations on the Internet, does not constitute one artwork but several works superimposed upon one another with limited points of interaction. On a first level is the initial concept, where creative intention is translated into the technological substructure through a hidden computer program. On another level the artwork, perceptible as such, is seen through the interface but even more it is lived and performed in its displayed form on-line. On a third level, there is the work as it is acted or perceived as the result of the device implementation via the interface. This multiple and fragmented character of the work promoted different levels of reappropriation by the artist and the computer programmer, various appropriations for each of the multiple dimensions of the device. From the artist's point of view, the artwork was within this "everything" that makes it possible: not only the idea, the concept, the interface, the engine, but also what the user sends, and the results of this are part and parcel of what the artist calls the plastic plan in its wholeness. Courvoisier, the computer programmer, agreed with the artist about the idea of the work's plural existence, but he was perhaps more concerned about isolating his own contribution.

Courvoisier: That's the problem because, in a certain way, we can say we work in an equal way. The work would not exist with- out the concept that aroused it, but the work would also not exist without the technical equipment that is set to realize it. When you know that it's the concept that comes before the artwork.... At this level we can say that whatever happens, the artist is always the real creator of the 
work.... Even if sometimes we can won- der if finally the work is related more to what I did or what he wanted to do?

In other respects, even Courvoisier recognizes Drouhin as the artwork's initiator, and if he experienced the feeling of producing a program in the service of a work of art, he nevertheless conceived this program from a perspective of autonomy and openness. For the programmer, the program's requirements of modularity and autonomy are liable to separate the tool from the artwork. The realization of the Des_Frags plan thus promoted both the production of a plastic creation and a computer application, a software tool that could be used again in a different context. The problem of appropriation, implicit throughout the plan's development, became inescapable when the question of authorship of the artwork intervened at the project's close. What can the artist claim as his property? If the work is this "everything" that constitutes the whole dispositiv, can the artist, for all that, remain the master of it?

Drouhin: I cannot say that he is a "co-artist" because that's not his function. He does not present himself this way either. I don't know how to say it. It's true that there's a problem here. If I know what to ask him, I don't know how to define his position.... But I'm going to put myself above him in the credits, sure, because I initiated the plan and then, at the end, the form it takes. But perhaps I'll put Sebastien [Courvoisier] above the CICV, I don't know, or on the same level.... Earlier I didn't know how to name him because I didn't want to say "technician." It doesn't please me at all. It's true that it's rather simplistic and reductionistic in light of the work he's doing, but we give a greater importance to the one who has the idea and that's obvious. But as far as the implications and exchanges we have are concerned, he enters the plan here, he gives ideas. 
Fig. 3. Screenshot of the Des_Frags credits. (@ Reynald Drouhin)

\section{des frags}

credits

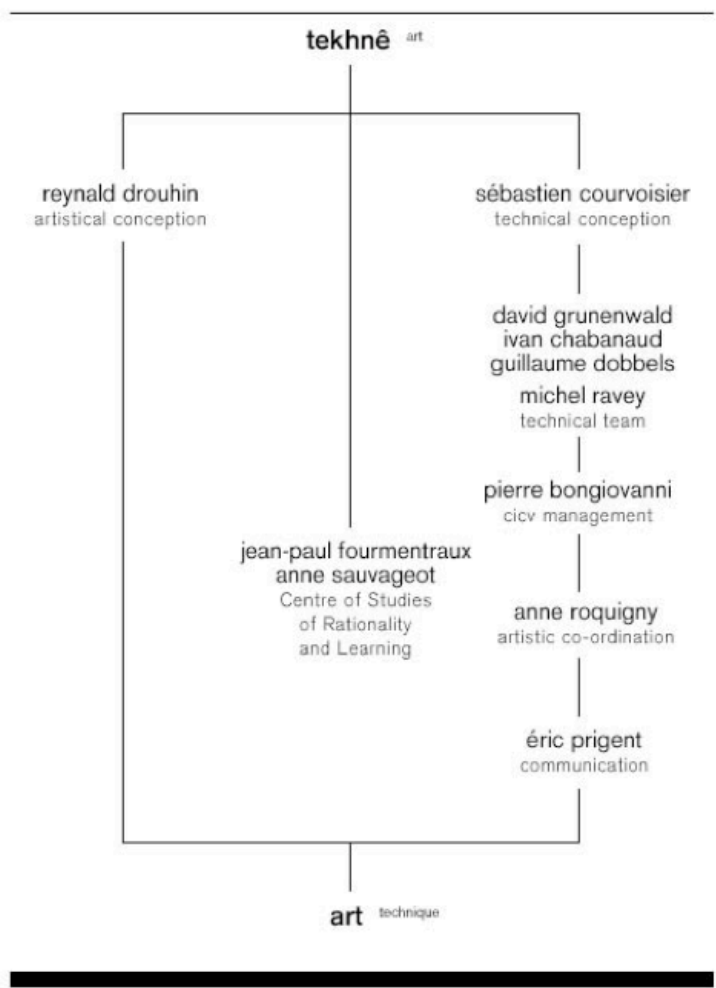

Drouhin's solution to these questions of authorship was to distribute the different actors and their contributions to the collective conception of the Des_Frags dispositiv along a "tekné/art" axis (Fig. 3). As in film credits, the whole "additional staff" who contributed to the artwork's realization is mentioned: from the direct actors of the artistic and technical conception to the institutional partners, communication agents and even to me, the sociological researcher, and my research supervisor. In contrast to film credits, the "crew" listings are not meant to be hierarchical but instead are shared on the vertical axis that goes from "tekné (art)," which refers to the 
practices in which artistic conception and technical skills are put on the same level, to the "art (technique)," which refers to the "rules of art," wherein artistic recognition occurs.

\section{THE WORK OF ART BEYOND THE INTERFACE}

This article attempts to highlight changes created by the "virtual" and "fragmented" regime unique to information technology and the effects of these changes on the traditional notion of the "work of art." The Des_Frags project exemplifies how, in this context, the work of art no longer presents the spectator with an ontological entity "already-there," within which artistic or technical talent and intention have crystallized. As a result, it is clear that, even though the interface is at the center of the artistic creation, it participates in the arrangement and composition of the artwork with the same status as the other elements. The interface functions to create a situation and embodies one of the elements that is part of a wider relationship with other elements such as the artist and the visitor, the computer and its peripherals (screen, keyboard, mouse), the programming algorithm, the source code, and the content's evolution (the material made available by the artist, brought by the visitor, generated by the machine or the network [11]). In other words, the interface can be regarded as a "body of work" shared by the artist, the machine and the Internet users. The existence of Des_Frags stems from the configuration of different fragments set in a dispositivthat includes a proscenium (the interface), a stage (the matrices, the thumbnails, the ephemeral gallery) as well as a backstage (not only the program, the fragments of preexisting applications, image stocks and search engines, but also the indefinite whole made up of potential images from the network that may be integrated into the system [12]). The concept of artistic dispositiv allows us to think about the superimposition of the different levels of this artwork. Moreover, its heuristic quality comes from its capacity to show the inclination of these various parts to function 
autonomously. In this respect, the layout "disposition" refers to the act of arranging the various elements that compose Des_Frags in a certain order; it also designates the result of this action. Understood as a machine and a mechanism, the dispositivsubsumes both the artistic act and its manifestation and, as a result, includes the possibilities of yet other approaches. On-line artworks simultaneously engage an aesthetic of code, an interface design and an art of the (ephemeral) archive. All on-line digital art will conjugate these three enunciative regimesand render available an "applied art" to the public.

This retrospective loop institutes a fully symmetrical distribution of roles for its three partners: the artist and programmer (who initiate and react to the process), the visitor (who actualizes the different versions of the dispositiv), and finally the work of art itself (which un- furls and manifests itself when in contact with the multiple "holds" [13], intentional or automatic). The dispositivs of Net Art contribute to the erasure of the barrier that separates the distinct entities of the producer and the consumer of an artwork. Neither truly rational, nor prohibitively determined, the viewer actively develops possible "holds" into the image and the artwork that he/she will be able to undo or redo. Potentially, this is only visible when actualized or, to use the language of the initiated, "performed." And in the course of this symmetrical process, the artwork, jointly activated by the program (the machine) and the actors of the interactive process(artist, programmer and user), finds itself capable of new functionalities. This type of artwork embodies the medium, the source of information and the environment where its "interactivities" and "interactions" spread and weave the relationships between the "agents" involved in the creative process.

\section{References and Notes}

1. H. Becker, Art Worlds(Berkeley, CA: University of California Press, 1982).

2. In the original French text this word is "dispositif," meaning, literally, 
"mechanism" or "device." Long mistranslated as "apparatus" in the field of film theory, this term would be better defined as a holistic phenomenon that encompasses both the cinematic apparatus, or mechanism, and the subject or viewer implicated in its functioning. Melita Zajc explores the question of this common mistranslation in her essay, "The Concept of Dispositiv: Studying Technology in Terms of Its Use. Because of the All Yet-to-Be-Written User Manuals" (available on-line at $<$ http://www.iwm.at/p-jvfcon.htm>). Zajc invented the term "dispositiv" to avoid this problem of mistranslation. In this text, I also translate this term “dispositif" as "dispositiv,"in order to avoid confusion.

3. Reynald Drouhin, Des_Frags $<$ http://desfrags. cicv.fr $>$.

4. Reynald Drouhin immersed himself in the Internet in 1995. Artworks such as Alteraction, Metaorigines and Des_Fragsdivert software, disrupt images and incorporate Internet errors and other intrigues. Drouhin's works often overlap and respond to one another. He is considered a major figure of French speaking Net Art.

5. CICV provides artists' residencies in electronic arts and organizes the International Festival of Multimedia Urban Arts, in Belfort, France $<$ www.inter ferences.org $>$. This multimedia and digital art festival is funded by the French Ministry of Culture.

6. C. Bessy and F. Chateauraynaud, Experts et faussaires. Pour une sociologie de la perception (Paris: Métailié, 1995).

7. A. Hennion and C. Méadel, "The Artisans of Desire: The Mediation of Advertising between the Product and the Consumer," Sociological Theory7, No. 2, 191-209 (1989); A. Hennion, La passion musicale. Une sociologie de la médiation (Paris: Métailié, 1993).

8. S-L. Star and J. Griesemer, 'Institutional Ecology, 'Translation,' and Boundary Objects: Amateurs and Professionals in Berkeley's Museum of Vertebrate Zoology, 1907-39," Social Studies of Science 19 (1989) pp. 387-420; "Les objets dans l'action. De la maison au laboratoire," in B. Conein, N. Dodier and L. Thévenot, eds., Raisons pratiques 4 (Paris: 
EHESS, 1994); M. Akrich, "Essay of Technosociology: A Gasogene in Costa Rica," in P. Lemonnier, ed., Technological Choices: Transformation in Material Cultures since the Neolithic(London: Routledge, 1993) pp. 289-337; M. Callon and J. Law, "Agency and the Hybrid "Collectif," South Atlantic Quarterly94, No. 2, 481-508 (1995).

9. A. Strauss, Negotiations: Varieties, Processes, Contexts, and Social Order(San Francisco: Jossey-Bass, 1978); M. Callon, "Struggles and Negotiations to Define What Is Problematic and What Is Not: the SocioLogics of Translation." in K. Knorr, ed., The Social Process of Scientific Investigation, Vol. 4 (Dordrecht, the Netherlands: Reidel Publishing Company, 1980) pp. 197-219; M. Callon, "Some Elements for a Sociology of Translation: Domestication of the Scallops and the Fishermen of St-Brieuc Bay," in J. Law, ed., Power, Action and Belief: a New Sociology of Knowledge?(London: Routledge, 1986) pp. 196-229.

10. This study succeeds previous works: J. Adler, Artists in Offices(New Brunswick, NJ: Transaction Inc, 1978); H. Collins and M. Kush, The Shape of Actions: What Humans and Machines Can Do(Cambridge, MA: MIT Press, 1998); N. Dodier, "Les appuis conventionnels de l'action. Éléments pour une pragmatique sociologique," Réseaux 62(1993); N. Dodier, Les hommes et les machines. La conscience collective dans les sociétés technicisées(Paris: Métailé, 1995); B. Latour and S. Woolgar, Laboratory Life: The Construction of Scientific Facts (Princeton, NJ: Princeton Univ. Press, 1986); B. Latour, Science in Action: How to Follow Scientists and Engineers through Society(Cambridge, MA: Harvard Univ. Press, 1987); B. Latour, "Drawing Things Together," in M. Lynch and S. Woolgar, eds., Representation in Scientific Practice(Cambridge, MA: MIT Press, 1990) pp. 19-68; D. Norman, The Design of Everyday Things(New York: Doubleday Currency, 1990); S. Shapin, “The Invisible Technician," American Scientist 77(1979); S-L. Star, "Working Together: Symbolic Interactionism, Activity Theory, and Information Systems," in D. Middleton and Y. Engestrom, eds., Cognition and Communication at 
Work (Cambridge, UK: Cambridge Univ. Press, 1997).

11. In this respect the experiments of Net Art build on the research of experimental cinema or video art by questioning what constitutes a work of art and violently shakesup the roles and functions attached to experimental cinema and video art.

12.In this process, the proscenium is the zone of action where the work can either be "played" or "undisplayed" via the interface: it is the visible element that operates the translation of the dispositiv. The stage then becomes the place of performance, shared by the artist and the "audience," where periodic and circumstantial manifestations of the work occur. The backstage area is reserved for the author-trio embodied by the machine, the artist and the computer programmer. Others have examined these new relations between artists and computer programmers: P-M. Menger, Les laboratoires de la création musicale (Paris: La Documentation française, 1989); P-M. Menger, "Artists as Workers: Theoretical and Methodological Challenges," Poetics28(2001) pp. 241-254; C. Harris, Art and Innovation: The Xerox Parc Artists-in-Residence Program(Cambridge, MA: MIT Press, 1999); G. Hutzler, B. Gortais and A. Drogoul, "The Garden of Chances: A Virtual Ecosystem," Leonardo33, No. 2, 101-107 (2000); J. Campbell, "Delusions of Dialogue: Control and Choice in Interactive Art," Leonardo33, No. 2, 133-140 (2000); J. Hamilton, Fields of Influence: Conjunctions of Artists and Scientists(Birmingham, U.K.: University of Birmingham Press, 2001).

13. In rock climbing, "holds" create an environment and are at the same time a result of action. Here it is also meant in reference to the "sociology of perception," or the "sociology of holds" explored in Bessy and Chateaurayand [6].

Jean-Paul Fourmentraux, Ph.D., is a researcher at the French National Center of Scientific Research (CNRS) and in the School of High Studies in Social Sciences (Paris: EHESS). He is the author of the book Art and Internet: The New Faces of Creation, published in October 2005 by CNRS. 